\title{
ANÁLISE DO DISCURSO DE UM RELATO PUBLICADO ACERCA DE UMA PRÁTICA PSICOSSOCIAL EM INSTITUIÇÃO PRISIONAL
}

DISCOURSE ANALYSIS OF A PUBLISHED REPORT ABOUT A PSYCHOSOCIAL PRACTICE ON A PRISIONAL INSTITUTION

ANÁLISIS DEL DISCURSO DE UN INFORME PUBLICADO ACERCA DE UNA PRÁCTICA PSICOSOCIAL EN UNA INSTITUCIÓN PENITENCIARIA

\section{Tamiris Amanda Rezende de Alvarenga* Yara Lombardi* Marilia Novais da Mata Machado ${ }^{* * *}$}

\begin{abstract}
RESUMO
Neste artigo, analisamos o relato publicado em 2009 de uma prática psicossocial ocorrida numa instituição prisional. Trata-se de um dos trabalhos proveniente de uma investigação mais ampla que considera as dimensóes epistemológicas, metodológicas e éticas de práticas psicossociais descritas em periódicos de Psicologia. Nosso objetivo foi analisar o discurso em um artigo científico concernente a uma prática psicossocial. Para isso, alguns critérios nortearam a seleção do texto analisado: ele apresenta uma prática que é simultaneamente de pesquisa e de intervenção, e tanto o método quanto os procedimentos éticos adotados foram explicitados. Investigamos se a prática descrita no referido relato foi capaz de construir operadores conceituais pertinentes, se ela apreendeu a estruturação e o funcionamento institucional em sua complexidade e se produziu conhecimento psicossocial, no que diz respeito à formulação de teoria, de métodos e de dispositivos, tanto de ação quanto de pesquisa.
\end{abstract}

Palavras-chave: Análise do discurso. Prática psicossocial. Metodologia. Epistemologia. Ética.

\section{ABSTRACT}

In this study, we analyzed a report published in 2009 about a psychosocial practice occurred in a penal institution. It is one of the works from a broader

\footnotetext{
Texto recebido em 25 de novembro de 2014 e aprovado para publicação em 25 de fevereiro de 2016.

"Mestra em Psicologia pela Universidade Federal de São João del-Rei (UFSJ), pós-graduanda pela Universidade Federal de Minas Gerais (UFMG). E-mail: tamirisarezende@yahoo.com.br.

**Mestra em Psicologia pela UFSJ, bacharel em Direito, discente isolada na disciplina Análise do Discurso. E-mail: yaralombardi@ hotmail.com.

*** Doutora pela Universidade de Paris Norte (Paris XIII). Filiação: UFMG (L@gir), UFSJ (Lapip). E-mail: marilianmm@gmail. com.
} 
investigation that considers the epistemological, methodological and ethical dimensions of psychosocial practices described in Psychology journals. Our goal was to analyze the discourse of a scientific article concerning a psychosocial practice. For this, some criteria guided the selection of the analyzed text: it presents a procedure that is at the same time for research and intervention and both the method and the ethical procedures adopted were brought into light. We investigated whether the procedure which was approached in the report was able to build up relevant operating concepts, whether it apprehended the structure and the institutional functioning in its complexity, and produced psychosocial knowledge regarding the formulation of a theory and methods and devices both for action and research.

Keywords: Discourse analysis. Psychosocial practice. Methodology. Epistemology. Ethics.

\section{RESUMEN}

En este trabajo, hemos analizado el informe publicado en el año 2009 de una práctica psicosocial que ocurrió en una prisión. Se trata de un trabajo proveniente de una investigación más amplia que considera las dimensiones epistemológicas, metodológicas y éticas de las prácticas psicosociales descritas en revistas de Psicología. Nuestro objetivo fue analizar el discurso en un artículo científico concerniente a una práctica psicosocial. Para eso, algunos criterios guiaron la selección del texto analizado: él presenta una práctica que es a la vez una investigación y una intervención y tanto el método como los procedimientos éticos adoptados fueron explicitados. Investigamos si la práctica descrita fue capaz de construir operadores conceptuales pertinentes, si ella aprehendió la estructura y el funcionamiento institucional en su complejidad y si se produjo conocimiento psicosocial en lo que se refiere a formulación de teoría, métodos y dispositivos tanto para la acción como para la investigación.

Palabras clave: Análisis del discurso. Práctica psicosocial. Metodología. Epistemología. Ética.

\section{INTRODUÇÃO}

$\mathrm{N}$

osso objetivo neste trabalho foi o de apresentar a análise do discurso de um artigo científico concernente a uma prática psicossocial. Entendemos por prática ou intervenção psicossocial o ato de intervir em contextos sociais, tais como grupos, associações, organizações, instituições, movimentos sociais ou 
comunidades, usualmente atendendo a uma demanda explícita ou implícita de um desses conjuntos sociais. A prática tem como finalidade, geralmente, tentar solucionar ou, ao menos, reduzir um possível mal-estar ou sofrimento social vivenciado pelos sujeitos participantes (Machado, 2004). Às vezes, é antecedida por uma oferta dos profissionais, como no caso analisado.

Nossa perspectiva acerca da intervenção psicossocial é bem próxima àquela proposta por Dubost (1987, p. 151), que define intervenção como "palavra que pode designar tanto uma ajuda, um suporte, uma mediação, um encontro, uma influência, um tratamento enérgico[...] quanto uma ingerência, uma intrusão, uma ocupação armada[...]". No que diz respeito às práticas de intervenção "psicossociológica", como ele a predica, Dubost (1987) indaga se elas

Estão, como se propõem, do lado da mudança, do movimento, da criação cultural, de um esforço anticonformativo, ou, ao contrário [...], do lado da ordem, da repetição, do reforço de comportamentos, da manutenção de um modo de dominação nas organizações? (p. 162).

O mesmo psicossociólogo afirma: "A presença ativa de um terceiro é necessária para o desenvolvimento de um verdadeiro trabalho de mudança" (Dubost, 1987, p. 173). Finalmente, o autor define intervenção psicossociológica como

Um trabalho de colaboração entre um conjunto [social] concreto que lida com fenômenos de natureza psicossociológica e sociológica, vividos como problema, e um profissional que intervém, individual ou coletivo, escolhido como consultor pelo conjunto (Dubost, 1987, p. 180).

Ainda para Dubost, o trabalho de intervenção psicossociológica é orientado para a análise e para a mudança das relações entre o conjunto social e os agentes da intervenção que almejam ter seus parceiros "como seres autônomos" (Dubost, 1987, p. 180).

Nossa análise indagou sobre os procedimentos e dispositivos de pesquisa e intervenção adotados na prática em foco, os aspectos éticos envolvidos e a capacidade de ela criar/produzir conhecimentos psicológicos e sociais. O trabalho insere-se em uma investigação mais ampla que considera as dimensões epistemológicas, metodológicas e éticas de práticas psicossociais descritas em periódicos de Psicologia. ${ }^{1}$ No caso aqui apresentado, foi realizada uma busca nos artigos publicados em Psicologia em Revista, da Pontifícia Universidade Católica de Minas Gerais (PUC Minas).

\footnotetext{
1 A pesquisa Práticas psicossociais: metodologia, epistemologia e ética cobre os seguintes periódicos: Psicologia e Sociedade (Abrapso); Estudos de Psicologia (UFRN); Aletheia (Ulbra); Fractal (UFF); Psicologia: ciência e profissão (CFP); Psicologia: teoria e prática (Universidade Presbiteriana Mackenzie); Arquivos brasileiros de Psicologia (UFRJ); Psicologia em Revista (PUC Minas); Psicologia e Politica (ABPP); Psicologia Social do Trabalho (USP); Pesquisas e práticas psicossociais (Lapip/UFSJ).
} 
O critério adotado para selecionar os estudos que tratavam de práticas psicossociais foi o fato de eles explicitarem teoria, metodologia e ética abraçadas. Um único estudo resultou dessa busca. Ele foi publicado por Boechat e Kastrup (2009), com o título A experiência com a literatura numa instituição prisional. Seu objetivo foi apresentar e discutir os efeitos de uma oficina de leitura feita com prisioneiros da unidade Hélio Gomes, do Complexo Penitenciário Frei Caneca, situado no Município do Rio de Janeiro. Nele, as escolhas metodológicas, epistemológicas e éticas fundamentais para a intervenção foram consideradas e descritas. Esse artigo foi o nosso corpus de pesquisa, ou seja, o material empírico sobre o qual realizamos nossa análise.

Nosso guia para a análise do discurso foram dois livros de Foucault (1996; 1987), respectivamente $A$ ordem do discurso e Arqueologia do saber. O primeiro nos levou a pensar o discurso como "realidade material de coisa pronunciada ou escrita" (Foucault, 1996, p. 8) e a análise do discurso como a descrição crítica (recobrimentos, ordenamentos, rarefações, negações, exclusões e interdições de linguagem) e genealógica (dispersões, descontinuidades, regularidades, positividades) do corpus analisado. O segundo livro nos levou a atentar para a formação discursiva das autoras, duas psicólogas, uma ("a pesquisadora”) mestranda, na época em que escreveu o referido artigo, e outra doutora. As duas estão ligadas à Universidade Federal do Rio de Janeiro, a primeira atenta à prática e a segunda uma teórica da subjetividade, da Psicologia cognitiva e da cartografia, com importante bagagem teórica, metodológica e epistemológica.

Apresentaremos, a seguir, o caminho que nos levou ao texto submetido à análise do discurso e algumas informações sobre o veículo em que a publicação surgiu.

\section{A SELEÇÃO DO CORPUS PARA A ANÁLISE E OUTRAS QUESTÓES DE MÉTODO}

Nossa intenção foi o de analisar todos os artigos relativos a práticas psicossociais publicados em Psicologia em Revista ao longo de cinco anos (2008 a 2012). Buscamos especificamente textos que articulavam pesquisa e intervenção, além de abordarem a questão ética, à qual atribuímos a mesma importância que às questôes teóricas e metodológicas. Na seleção dos artigos, adotamos os seguintes critérios: presença de detalhamento e discussão da prática, presença de pesquisa e de intervenção e de avaliação da prática. Assim, excluímos da análise todos os artigos que desconsideraram descrições metodológicas, teóricas, epistemológicas e de cuidados éticos. 
Vale ressaltar que o critério de seleção restrito a cinco anos foi adotado temendo-se a quantidade de material a ser examinado, o que poderia prorrogar demasiadamente a realização da pesquisa e, ainda, não permitiria uma reflexão minuciosa relativa à articulação de metodologia, teoria, epistemologia e ética. Além disso, a ênfase sobre artigos mais recentes supostamente nos leva a textos mais trabalhados dos pontos de vista teórico, epistemológico, metodológico e ético, temas que apenas na atualidade vêm sendo considerados com mais afinco no que diz respeito às práticas.

Os demais critérios de seleção foram fundamentados nos argumentos encontrados em Machado (2011), que discute a posição atual das práticas psicossociais no âmbito da produção de conhecimento científico. Segundo a autora, questôes envolvendo método, técnicas e procedimentos, nessas práticas, estão bem encaminhadas, assim como a questão teórica, que vem apresentando avanços por utilizar aportes provenientes de várias áreas do conhecimento. Porém, no que se refere à avaliação e ao registro das práticas, bem como ao seu estatuto epistemológico, a autora reitera que ainda há desafios que precisam ser vencidos.

Ao buscarmos trabalhos que traziam em seu título a palavra "prática", encontramos sete artigos em Psicologia em Revista: Melo e Rocha (2008), Hillesheim, Somavilla, Dhein, e Lara (2009), Moreau (2009), Silveira (2009), Santos (2012), Vieira e Branco (2010), Campos (2012). Examinamos cuidadosamente o resumo de cada um deles, a fim de verificar se a prática reportada no título se caracterizava como uma pesquisa-intervenção psicossocial e se esta, por sua vez, aproximava-se dos nossos critérios preestabelecidos. Nenhum desses artigos foi selecionado. Uns por não se tratarem de uma intervenção propriamente dita, outros por não se ocuparem com os requisitos exigidos nesta pesquisa.

Depois disso, optamos por verificar todos os outros artigos publicados ao longo dos cinco anos e que haviam ficado fora da primeira seleção. Fizemos uma leitura minuciosa de seus resumos, na tentativa de encontrar os que se reportavam a alguma prática psicossocial. Nesse momento, cinco estudos foram selecionados: Boechat e Kastrup (2009), Brito (2009), Dias e Bighetti (2009), Dias, Cunha e Enumo (2010), Almeida-Verdu e Santos (2012).

Obedecendo ao conjunto de critérios elencados, entre todos os artigos examinados, apenas um, A experiência com a Literatura numa instituição prisional, de Boechat e Kastrup (2009), adequou-se aos critérios preestabelecidos e, dessa maneira, foi selecionado para ser submetido à análise do discurso. Sua escolha resultou da leitura integral e cuidadosa de todos os outros. Procuramos cumprir a proposta da pesquisa, isto é, apreender as técnicas, teorias, epistemologia e 
metodologia utilizadas, assim como os cuidados éticos observados nas pesquisasintervenções. Simultaneamente, nossa atenção voltou-se também à linguagem neles utilizada. Assim, quando necessário e pertinente, valemo-nos de marcadores $\mathrm{da}$ análise do discurso, para responder às questóes que despontaram relativas a texto e a contexto. Buscamos responder às perguntas elencadas a seguir, sugeridas em nosso projeto de pesquisa:

a) Fica claro, no artigo, se a intervenção parte de uma demanda dos sujeitos envolvidos? Se sim, em que contexto a demanda aparece? Que temas são trabalhados? São problemas a resolver? São sintomas subjacentes a problemas verdadeiros? Se não, como surge a demanda? Que eventos precedem a intervenção? Como ocorre a relação pesquisador/consultor vis-à-vis conjunto social? A prática é dirigida pelo pesquisador? O conjunto social participa? De que maneira?

b) Que procedimentos, técnicas e métodos são usados? Que aparato conceitual é empregado? Qual é o objeto da prática?

c) Que lugar a pesquisa ocupa na prática psicossocial? Como são feitas as observações? São feitas indagações e interpretaçôes? As interpretações são confrontadas com o conjunto de observações empíricas? O registro de observaçōes é feito de forma precisa, consistente e exaustiva? Há um distanciamento entre pesquisador e conjunto social? Qual é o papel da subjetividade (do pesquisador, dos participantes) na prática? Como o pesquisador lida com as suas próprias implicaçôes? Há discussão em grupo?

d) Como o contexto em que a prática ocorre é descrito? É usado o diário de campo? Como são feitos os registros dos procedimentos? Conhece-se o contexto e a história do conjunto social? De que forma os resultados são apresentados? São avaliadas possibilidades de generalização dos resultados?

e) De um ponto de vista ético, em que a prática social contribui para o conjunto social?

Ao buscarmos informação sobre teoria, método, produção de conhecimento e ética, verificamos que um ou mais desses tópicos estavam ausentes nos artigos de Brito (2009), Dias e Bighetti (2009), Dias, Cunha e Enumo (2010), AlmeidaVerdu e Santos (2012). Concentramo-nos, assim, no texto de Boechat e Kastrup (2009), buscando responder às perguntas acima.

Antes, porém, de apresentarmos nossa descrição do artigo, trazemos alguns dados sobre o periódico que o veicula. Essas informações de contexto foram obtidas no site da revista e se referem aos antecedentes de sua criação, ao público ao qual se destina, entre outras. 


\section{PSICOLOGIA EM REVISTA}

Nascido em dezembro de 1993 e nomeado inicialmente Cadernos de Psicologia, o periódico da Faculdade de Psicologia da Pontifícia Universidade Católica de Minas Gerais (PUC Minas), Psicologia em Revista (conforme é denominado desde 2002) abre-se não apenas para as práticas e teorias da Psicologia, mas também para campos afins, da academia ou não, para graduandos ou pós-graduandos, brasileiros ou não. Dessa maneira, procura abranger o maior número possível de interessados, a fim de promover uma articulação com outras áreas das Ciências Sociais e Humanas.

De publicação quadrimestral e de cunho generalista, Psicologia em Revista é classificada atualmente como B1 para a área de Psicologia. Vale ressaltar que tal classificação se deve a critérios da Capes/Qualis, podendo, portanto, variar de acordo com as diferentes áreas e a cada avaliação. É periódico bilíngue que aceita artigos em português e espanhol, além de traduzir textos do inglês e do francês.

Sua comissão editorial é formada por docentes doutores do Programa de Pós-Graduação em Psicologia da PUC Minas e seu corpo editorial científico é composto por professores e pesquisadores de renomadas universidades brasileiras, assim como de universidades e centros de pesquisa internacionais. Da mesma forma, os consultores ad hoc são doutores tanto de instituições brasileiras quanto estrangeiras.

Em 2008, a revista implantou a publicação de resumos nas seguintes línguas: português, inglês e espanhol. Ainda nesse ano, ela passou a ser divulgada tanto em formato impresso quanto on-line, no portal da PUC Minas. Atualmente o formato on-line é exclusivo. Desde 2005 a revista é divulgada pelo portal dos Periódicos Eletrônicos em Psicologia (Pepsic) e, desde 2008, utiliza o Sistema Eletrônico de Editoração de Revistas (SEER).

Em 2009, passou a publicar 30 artigos originais por ano. Os tipos de colaboração aceitos são divididos em duas grandes seções:

a) seção de artigos, que comporta relatos de pesquisa, revisões de literatura, estudos teóricos, relatos de experiência profissional;

b) seção aberta, para a qual são aceitas várias categorias de trabalho, como artigos ou textos de autores estrangeiros, já publicados em outros países, desde que inéditos em língua portuguesa; resenhas de publicações nacionais ou estrangeiras; resumos de teses e dissertaçóes; entrevistas com profissionais da Psicologia e áreas afins; conferências ministradas em eventos relevantes; outras contribuições relativas a eventos científicos, questões técnico-científicas e sociais relevantes para a área da Psicologia. 
Enfim, trata-se de uma revista acadêmica, aberta a diferentes posturas teórico-metodológicas, rigorosa na aplicação de critérios editoriais e muito bemconceituada nas áreas de Psicologia e afins.

\section{DESCRIÇÃO DO ARTIGO}

A experiência com a literatura numa instituição prisional, artigo de Boechat $\mathrm{e}$ Kastrup (2009), resulta da implantação e desenvolvimento de uma oficina de leitura realizada com presidiários do Complexo Penitenciário Frei Caneca, na unidade prisional Hélio Gomes. Sua finalidade foi promover, por meio da arte, especificamente da literatura, a produção da subjetividade e a transformação social num meio de privação e violência, como é o da prisão. Baseada em um convênio feito entre a Divisão de Psicologia Aplicada da Universidade Federal do Rio de Janeiro (UFRJ) e a Secretaria do Estado de Administração Penitenciária (SEAP), a oficina foi realizada ao longo de 16 meses, entre 2006 e 2008, coincidindo com o estágio da pesquisadora e primeira autora do artigo, então aluna de Psicologia.

Fundamentadas em informações sobre o sistema carcerário brasileiro (sobretudo do Estado do Rio de Janeiro) e tendo como referência teorias de Foucault, Wacquant e Goffman sobre prisão, de Deleuse, Guattari, Rolnik e Kastruf sobre oficina e subjetividade, e de Foucault sobre modos de subjetivação, as autoras apresentaram como características do referido complexo penitenciário a superlotação e as condições de vida sub-humanas. Referiram-se igualmente à violência diária e à falta de assistência à população carcerária, fazendo um paralelo com a situação nacional. Avaliando a situação local do Rio de Janeiro, sugeriram intervençôes voltadas à redução da criminalidade e ao desenvolvimento de projetos que atendessem às populações carcerárias e às famílias dos detentos, juntamente com avaliações sobre os efeitos dessas intervenções. $\mathrm{O}$ intuito foi o de "Romper com a lógica viciosa de marginalização da pobreza" (Boechat \& Kastrup, 2009, p. 26).

Aprofundando a crítica, as autoras explicitaram que a prisão exerce efeitos sobre os sujeitos e, acompanhado teorização foucaultiana, afirmaram que "O cuidado de si, essa estética da existência, apresenta-se por esquemas criativos de sobrevivência e convívio naquele espaço" (Boechat \& Kastrup, 2009, p. 27). Isso produz formas diversas de existir e de se transformar.

As autoras observaram que, nesse meio prisional carente de recursos, tanto com relação a produtos quanto com relação à assessoria, onde geralmente se espera apenas ócio e disposição para o crime, existia também uma potencialidade inventiva sobre as maneiras de agir e de ser, além de interesse em praticar alguma atividade durante o tempo disponível. Nessas circunstâncias, era possível realizar 
alguma ação que promovesse uma pausa no dia a dia dos presidiários para uma experiência com eles mesmos, segundo a proposta de oficina. Devido à dificuldade de entrar nas penitenciárias com objetos, a ideia dos livros se mostrou prática e promissora, uma vez que a leitura serviria de instrumento para viabilizar a transformação da subjetividade e do meio, segundo as autoras.

O valor da leitura para a promoção de experiências cognitivas, afetivas e comportamentais naqueles que a exercem já se encontra fundamentado em teorias de Guattari e Rolnik, e de Kastrup, entre outras. Com isso, inicialmente, foi feita a proposta de realizar a oficina de leitura noutra instituição prisional, trabalho que, contudo, foi interrompido pela contratante, alegando que essa não era uma prática de Psicologia. Depois disso, a unidade prisional Hélio Gomes foi procurada e aceitou a proposta. Mesmo assim, devido a entraves burocráticos e ideológicos, as atividades tiveram início somente depois de nove meses.

Para a oficina foram selecionados textos de autores clássicos, como Graciliano Ramos, Jorge Luis Borges e Edgar Allan Poe, antevendo que o encontro com essas leituras bem como a discussão com os colegas pudessem propiciar um espaço de promoção de vivências de cunho afetivo, emocional e cognitivo. A princípio, a escolha dos textos foi feita pela própria pesquisadora, visando a despertar falas sobre experiências individuais e coletivas. Posteriormente, alguns livros foram emprestados aos presos para que eles pudessem ler em suas celas e escolher a leitura do encontro seguinte. Nesse caso, a escolha seria justificada no momento das oficinas.

Os encontros, coordenados pela pesquisadora, ocorreram semanalmente, por cerca de duas horas, na escola ou na capela da instituição, de acordo com a disponibilidade desses espaços, e contaram com a presença de nove internos. Entre esses, no decorrer do trabalho, três saíram e outros três ocuparam esses lugares. Eles tinham entre 28 e 52 anos, graus diferentes de escolaridade e foram selecionados segundo os seguintes critérios: alta durabilidade da pena (o que garantia maior tempo de participação no grupo) e não recebimento de visitas (o que lhes intensificava a angústia, tornando mais difícil a espera pela libertação). Tais critérios foram adotados a partir de dados de exames criminológicos e de discussões com a supervisão. Os internos até aquele momento somente tinham tido contato com leituras da Bíblia e livros de autoajuda.

A ida para a oficina era de responsabilidade dos guardas do turno. Esse trânsito permitiu que se conhecesse a relação conturbada entre presos e guardas, marcada por insultos e desafetos. O trajeto era permeado por perturbações. Os internos, ao saírem de suas celas e ao retornarem a ela, passavam por outra, menor, que eles chamavam de "gaiola", onde aguardavam horas, sem comida e sem bebida, 
até serem retirados e levados ao destino. Tratava-se de um lugar geralmente superlotado, sem higiene e foco de provocaçōes entre os presidiários. A travessia entre esses espaços justificaria uma possível desistência ou desinteresse pela oficina. No entanto isso não foi empecilho para a manutenção das atividades, uma vez que os participantes permaneceram na oficina mesmo podendo passar por esses transtornos.

Nos relatos dos encontros, foi possível notar que a pesquisadora abriu espaços para avaliações dos membros com relação ao funcionamento da oficina e questionou sua própria prática e seus efeitos, como quando suscitou a dúvida de estar talvez propondo um texto com uma linguagem muito formal, o que dificultaria a compreensão durante as leituras. Mas sua contribuição em esclarecer as palavras desconhecidas colaborava para o entendimento.

Durante os encontros, os presos tinham liberdade para opinarem, interpretarem os textos, desabafarem sobre o que sentiam, já que associavam, muitas vezes, suas experiências e relacionamentos às estórias lidas. Isso possibilitou à pesquisadora um maior conhecimento sobre a realidade vivenciada por esses sujeitos no dia a dia, dentro e fora dos presídios. As questões que emergiram nas discussões em grupo, como o fato de outros internos quererem participar da oficina e as transferências realizadas a partir dos textos, foram sendo guiadas e controladas pela pesquisadora, sempre atenta em respeitar a subjetividade dos pesquisados.

Essa relação entre pesquisadora e participante forjada pela oficina se deu de maneira adequada, uma vez que todos pareceram respeitar o lugar e o papel de cada um no grupo. Podemos dizer que isso proveio dos cuidados éticos tomados pela pesquisadora e demais envolvidos no projeto. Logo no início das atividades, foi demarcado o objetivo proposto pela oficina, deixando-se claro que a participação nela não acarretaria em benefício judicial ou algo dessa ordem. Tomou-se também o cuidado de se utilizar uma linguagem menos formal para estreitar a relação, bem como se buscou evitar a ideia de que o objetivo das leituras era agregar conhecimento ou cultura.

Além das avaliações regulares, houve o desfecho das atividades em que, mais uma vez, os participantes puderam se expressar a respeito do grupo. Os relatos apontaram os efeitos provocados. Um dos mais marcantes foi a rede de leitores que se formou na unidade prisional. Com o tempo, não apenas os membros da oficina liam e discutiam os textos, mas também seus colegas de cela. Isso permitiu uma expansão da proposta para outros prisioneiros. Foram despertados sentimentos, desabafos, "abertura de mentes", emoções diretamente ligadas à leitura (como a dúvida se o texto terminara ou não e as interpretaçôes acerca do final das estórias). A possibilidade de caminhar pelo presídio, além da própria 
presença na oficina, permitiu lidar com fatores ansiogênicos. Além disso, um dos presos participantes retornou às aulas.

Recorrentemente, porém, os internos falaram sobre ganhos e expectativas de pareceres favoráveis nas avaliaçôes judiciais, mesmo tendo sido anteriormente comunicados de que a oficina não colaboraria para isso. Ademais, a literatura ficou em último lugar na lista de considerações com relação aos motivos para frequentarem a oficina. Todavia os itens elencados indicaram compromisso com o trabalho ofertado e, também, mostraram relação, mesmo que indireta, com as leituras, apontando efeitos positivos da oficina.

Os resultados foram contrapostos às teorias de Deleuze e Guattari, e de Kastrup. A descrição da unidade prisional, do trânsito dos detentos no caminho das oficinas, bem como de alguns dos encontros esclareceu os procedimentos de intervenção adotados, as circunstâncias em que foram feitos e os seus efeitos.

\section{CONSIDERAÇÕES FINAIS}

Cabe-nos agora voltar às nossas questões de pesquisa. De fato, a prática relatada no artigo construiu um operador conceitual importante (a oficina de leitura) que funcionou de forma a permitir observar e definir diretamente um objeto (o aprisionamento) e, simultaneamente, realizar prática que mudou esse objeto, ainda que dentro de limites estritos. O operador evidenciou a construção de novas subjetividades e de novos modos de subjetivação e possibilitou, dentro de uma instituição de disciplina rigorosa, novas formas de vivências, certa escolha (a de ler ou não), formas singulares e coletivas de dar o tom à leitura, de se comportar dentro do presídio, de criar vínculos novos (por exemplo, encontros entre os participantes da oficina durante os banhos de sol). Ajudou, portanto, a construir teoria e a promover mudança social positiva, não apenas de nove detentos, mas também em seu entorno.

A descrição do trânsito dos presidiários da unidade Hélio Gomes no caminho para as oficinas revelou parte da estruturação e do funcionamento institucional da prisão, em sua complexidade. Produziu, assim, também, conhecimento psicossocial que pode vir a apoiar formulação de teoria, de métodos e de dispositivos, tanto de ação quanto de pesquisa.

A oficina não partiu de uma demanda dos sujeitos, mas de uma oferta da pesquisadora em seu trabalho de estagiária universitária. Foi também da pesquisadora a ideia de pesquisar subjetividade. Observamos que, da proposta à execução, o direcionamento das atividades a colocou em lugar central na montagem da intervenção, sem real coparticipação dos presidiários, ouvidos 
apenas dentro de limites muito estreitos. Por se tratar de oficina em uma instituição prisional, talvez as coisas não pudessem ser diferentes. De fato, os presos não gozam de qualquer autonomia e não se lhes permite antecipar livremente nenhuma emancipação. Tampouco a prática rompeu com a estrutura opressiva da prisão. Mas nada disso invalida o resultado da intervenção, positivo, como descrito no artigo.

No que diz respeito aos procedimentos, técnicas e métodos utilizados, eles são descritos com cuidado. Mas restaram lacunas. Há muitos indícios no artigo de que os encontros foram anotados detalhadamente, mas não ficou claro como e quando esses registros foram realizados, se as sessões foram gravadas ou não e que procedimentos foram adotados para a realização da crônica dos acontecimentos. De um ponto de vista metodológico, no relato do trabalho, faltaram informações relativas ao registro das atividades.

Mas o aparato conceitual está claro. Nossa análise nos levou a considerar que a descrição dos encontros atesta intimidade com o método cartográfico, atenção à expansão da subjetividade dos participantes e compartilhamento de experiências entre detentos e pesquisadora, no contexto da oficina de leitura. Da mesma forma, objeto e objetivo da prática foram explicitados: a questão da subjetividade, a tentativa de construir dispositivos visando, dentro dos limites institucionais, ao fim dos horrores da prisão.

O estabelecimento do vínculo entre pesquisa, teoria e prática é o ponto alto do artigo. A oficina de leitura é instância que permite observação rigorosa e, além disso, permite registrar a observação. Como vimos, a forma de registrar não foi descrita de forma precisa, consistente e exaustiva, mas sabemos como a própria escrita de um artigo, subordinado a numerosas regras editoriais, limita a quantidade de informação que pode ser transmitida.

Outra lacuna para o leitor diz respeito ao deslocamento entre as celas e a "gaiola" e entre a gaiola e a oficina, trajeto que expunha os participantes a situações desagradáveis e constrangedoras, em "condiçõos desumanas" (Boechat \& Kastrup, 2009, p. 36), como descrevem as autoras. Apesar das informações nos parecerem insuficientes, o relato permitiu entender que o deslocamento voluntário dos presos indicava afetos positivos criados entre eles e deles com a leitura, como podemos pressupor da citação que se segue:

Após o encontro, saíam diretamente da escola para a "gaiola" e lá esperavam serem levados de volta para a cela. $\mathrm{O}$ encontro era realizado na parte da manhã, e os internos aguardavam naquele cubículo imundo até quatro horas sem se alimentar, e ainda sofriam ameaças e provocações. [...] Todos concordavam que frequentar a oficina era arriscado. Além disso, a postura de concentração e envolvimento não parecia em nada com uma simples atitude de evadir de suas celas apenas para "passar o tempo" (Boechat \& Kastrup, 2009, p. 36). 
No que se refere aos cuidados éticos adotados, ressaltamos o valor das avaliaçôes regulares feitas com o grupo, a fim de sentir e direcionar o andamento das tarefas; o rapport estabelecido inicialmente; o uso de linguagem informal para estreitamento dos vínculos sociais e redução de barreiras entre a coordenadora e os membros da oficina; o cuidado de não incutir a ideia de que as leituras teriam a finalidade de agregar valor ou cultura. Esses elementos foram fundamentais para o estabelecimento de práticas saudáveis e transformadoras.

Salientamos também a rede de leitores formada ao redor da oficina de leitura. Entendemos que essa participação não presencial expandida entre os prisioneiros de celas diferentes prova o sucesso da oficina como prática psicossocial. Isso porque ampliou a possibilidade de outros detentos experimentarem os efeitos da criação de novos modos de subjetivação. Práticas como essa, além de colaborarem para a produção de conhecimento auxiliando na formulação de teorias, métodos e dispositivos operacionais, contribuem para a melhoria do cenário psicossocial de todos os envolvidos, demonstrando sua significância em ambientes de privaçôes e controle como o são os presídios. 


\section{Referências}

Almeida-Verdu, A. C. M. \& Santos, S. de L. R. (2012). Leitura em uma criança surda após equivalência de estímulos. Psicologia em Revista, 18(2), 209-226. Recuperado a partir de http://periodicos.pucminas.br/index.php/ psicologiaemrevista/article/view/P.1678-9563.2012v18n2p209/5018

Boechat, M. \& Kastrup, V (2009). A experiência com a literatura numa instituição prisional. Psicologia em Revista, 15(3), 22-40. Recuperado a partir de http://periodicos.pucminas.br/index.php/psicologiaemrevista/article/view/ P.1678-9563.2009v15n3p22/954

Brito, D. C. S. de (2009). A orientação profissional como instrumento reabilitador de pacientes portadores de doenças crônicas e deficiências adquiridas. Psicologia em Revista, 15(1), 106-119. Recuperado a partir de http://periodicos.pucminas. br/index.php/psicologiaemrevista/article/view/P.1678-9563.2009v15n1p106

Campos, G. W. deS. (2012). Apoio matricial e práticas ampliadas e compartilhadas em redes de atenção. Psicologia em Revista, 18(1),148-168. Recuperado a partir de http://periodicos.pucminas.br/index.php/psicologiaemrevista/article/ view/385/4155.

ias, N. M. \& Bighetti, C. A. (2009). Intervenção em habilidades metafonológicas em estudantes do ensino fundamental e desenvolvimento de leitura. Psicologia em Revista, 15(3), 140-158. Recuperado a partir de http:// periodicos.pucminas.br/index.php/psicologiaemrevista/article/view/P.16789563.2009v15n3p140/960.

Dias, T. L, Cunha, A. C. B. da, \& Enumo, S. R. F. (2010). Avaliação cognitiva por provas assistidas em crianças com necessidades educativas especiais. Psicologia em Revista, 16(3), 594-612. Recuperado a partir de http:// periodicos.pucminas.br/index.php/psicologiaemrevista/article/view/P.16789563.2010v16n3p594/2222

Dubost, J. (1987). Lintervention psychosociologique. Paris: PUF.

Foucault, M. (1987). A arqueologia do saber. L. F. B. Neves (Trad.). Rio de Janeiro: Forense-Universitária.

Foucault, M. (1996). A ordem do discurso: aula inaugural no Collège de France, pronunciada em 2 de dezembro de 1970. São Paulo: Loyola. 
Hillesheim, B., Somavilla, V. da C., Dhein, G., \& Lafa, L. (2009). Saúde da mulher e práticas de governo no campo das políticas públicas. Psicologia em Revista, 15(1), 196-211. Recuperado a partir de http://periodicos.pucminas.br/index. php/psicologiaemrevista/article/view/P.1678-9563.2009v15n1p196/646.

Machado, M. N. M. (2004). Práticas psicossociais: pesquisando e intervindo. Belo Horizonte: Edições do Campo Social.

Machado, M. N. M. \& Pires, S. D. (2011). Indagações sobre epistemologia e metodologia das práticas psicossociais. In Anais do 16 Encontro Nacional da Abrapso. Recife: Abrapso. Recuperado a partir de http://www. encontro2011.abrapso.org.br/trabalho/w?q=YToyOntzOjY6InBhcmFtcyI7 czozNToiYToxOntzOjExOiJJRF9UUkFCQUxITyI7czozOiIxMDciO30iO 3M6MToiaCI7czozMjoiOTUxNjZiMTQxNWNjNjBkNGJkMzc5MjQyMDIwODZkZGUiO30\%3D

Melo, P. L. de \& Rocha, M. L. de. (2008). Poder e trabalho na escola: práticas inclusivas de discussão. Psicologia em Revista, 14(2), 81-94. Recuperado a partir de http://periodicos.pucminas.br/index.php/psicologiaemrevista/article/ view/332/360.

Moreau, D. (2009). Conjurar a qualificação da violência: justificativas e práticas do recurso à coerção nas hospitalizações psiquiátricas. Psicologia em Revista, 15(3), 1-21. Recuperado a partir de http://periodicos.pucminas.br/index.php/ psicologiaemrevista/article/view/P.1678-9563.2009v15n3p1/953.

Santos, M. A. G. dos (2012). A prática da terapia cognitivo comportamental baseada em mindfulness e aceitação. Psicologia em Revista, 18(3), 527530. Recuperado a partir de http://periodicos.pucminas.br/index.php/ psicologiaemrevista/article/view/3622/5269.

Silveira, R. D. (2009). Projeto Lopes Rodrigues: continuidades e rupturas nas conexôes entre ensino psiquiátrico e prática assistencial em Minas Gerais 1920-1930: resumo de tese. Psicologia em Revista, 15(1), 246-248. Recuperado a partir de http://periodicos.pucminas.br/index.php/psicologiaemrevista/ article/view/628/649.

Vieira, A. O. M. \& Branco, A. U. (2010). Cultura, crenças e práticas de socialização de gêmeos monozigóticos. Psicologia em Revista, 16(3), 575-593. Recuperado a partir de http://periodicos.pucminas.br/index.php/psicologiaemrevista/ article/view/P.1678-9563.2010v16n3p575/2236 